\title{
CORONARY VASCULAR REGULATION DURING POSTCARDIOPLEGIA REPERFUSION
}

Edward R. Ferguson, MD Russell D. Spruell, BSEE Walter V. A. Vicente, MD, PhD C. Patrick Murrah, MD William L. Holman, MD
Background: This study extends previous investigations of global and regional myocardial blood flow during early postcardioplegia reperfusion. The hypothesis tested is that coronary vascular regulation becomes abnormal within 3 minutes after the start of postcardioplegia reperfusion. Methods: Pigs $(n=40)$ were supported by cardiopulmonary bypass and $38^{\circ} \mathrm{C}$ blood cardioplegic solution was infused. A control preischemic microsphere injection (No. 1) was given in asystolic hearts. Groups 1 to 3 had 1 hour of hypothermic cardioplegic arrest. Group 4 (control group) had 1 hour of perfusion without cardioplegia. A blood cardioplegic solution at $38^{\circ} \mathrm{C}$ and $70 \mathrm{~mm} \mathrm{Hg}$ pressure was infused to maintain asystole during the initial $\mathbf{7}$ to $\mathbf{1 0}$ minutes of reperfusion in all groups. Left ventricular intracavitary pressures were set at $0,10,20$, or $0 \mathrm{~mm}$ $\mathrm{Hg}$ in groups $1,2,3$, and 4 ( $n=10$ pigs per group), respectively, during the initial 7 minutes of reperfusion. The ventricle was then decompressed. At 30 seconds, 3 minutes, and 6 minutes after reperfusion, microsphere injections 2 , 3 , and 4 were given in asystolic hearts. Microsphere injection No. 5 was given 10 minutes after reperfusion in beating vented hearts. Results: (1) Left ventricular distention during the initial 7 minutes of reperfusion after hypothermic cardioplegic arrest attenuates postischemic hyperemia. (2) Left ventricular intracavitary pressure of $20 \mathrm{~mm} \mathrm{Hg}$ during reperfusion causes a decrease in endocardial blood flow relative to epicardial blood flow at 6 minutes after reperfusion. (3) Global myocardial blood flow during postcardioplegia reperfusion falls significantly below preischemic control values despite the return of electromechanical activity. Inference: Coronary vascular regulation (i.e., coronary resistance and metabolic flow recruitment) becomes abnormal within 3 minutes after the start of reperfusion after hypothermic blood cardioplegic arrest. (J Thorac Cardiovasc Surg 1996;112:1054-63)
$\mathrm{M}$ any factors affect global myocardial blood flow and regional blood flow distribution. Heart rate, ${ }^{1}$ heart rhythm (e.g., ventricular fibrillation or asystole), ${ }^{2-5}$ time during postischemic reperfusion, ${ }^{6}$

From the Department of Surgery, Division of Cardiothoracic Surgery, University of Alabama at Birmingham, Birmingham, Ala.

Supported by U.S. Public Health Service grant HL 43213 and a grant from $\mathrm{CNPq}$ Conselho Nacional de Desenvolvimento Cientifico e Tecnologico, Brazil. This work was performed during Dr. Holman's tenure as an Established Investigator for the American Heart Association.

Received for publication Jan. 9, 1996; revisions requested Feb. 21, 1996; revisions received March 14, 1996; accepted for publication April 23, 1996.

Address for reprints: William L. Holman, MD, Department of Surgery, University of Alabama at Birmingham, University Station, Birmingham, AL 35294-0007.

Copyright (c) 1996 by Mosby-Year Book, Inc.

$0022-5223 / 96 \$ 5.00+0 \quad \mathbf{1 2} / \mathbf{1} / \mathbf{7 4 3 3 0}$ adequacy of myocardial protection during cardioplegic arrest, ${ }^{7}$ aortic root pressure, ${ }^{8}$ and left ventricular cavitary pressure during postcardioplegia reperfusion ${ }^{9,10}$ have all been shown to influence global and regional myocardial blood flow. More recently, studies of coronary endothelium have documented the important influence that these cells have on the myocardial vasculature. These studies have shown that endothelial function is deranged after cardioplegic arrest and reperfusion. ${ }^{11-14}$

Our laboratory previously examined the effect of postcardioplegia reperfusion rhythm on myocardial blood flow using an in situ porcine model. ${ }^{15}$ In this experiment, global myocardial blood flow decreased below preischemic control levels during the initial 15 minutes of reperfusion. Furthermore, myocardial blood flow did not respond to the resumption of electromechanical activity (i.e., reperfusion ventricular fibrillation or an organized rhythm) after 3 minutes of reperfusion. It was inferred from these 


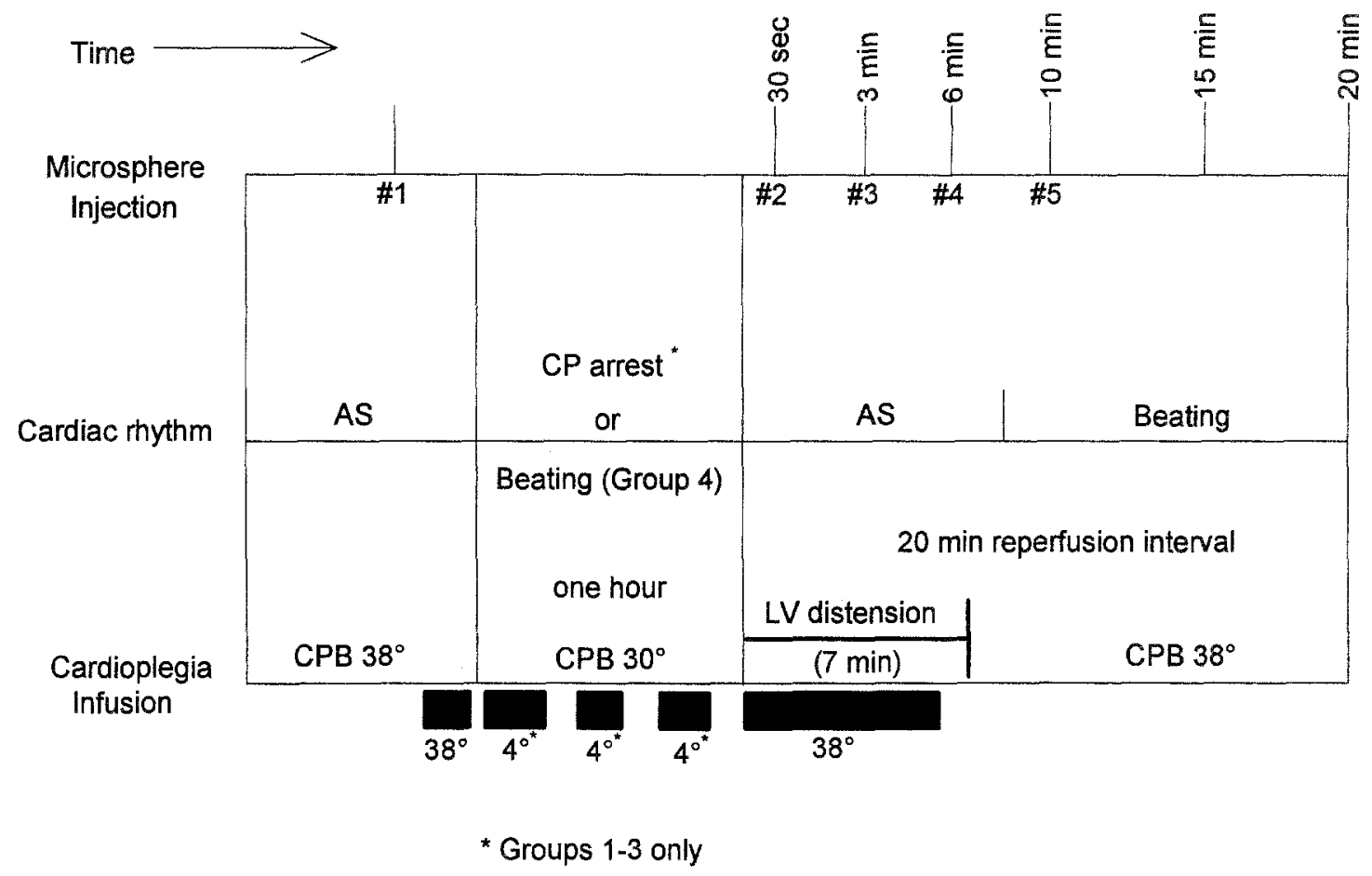

Fig. 1. The experimental protocol is summarized in this diagram. Microsphere injection No. 1 was given during infusion of a $38^{\circ} \mathrm{C}$ cardioplegic solution that produced asystole. In groups 1 to 3 , there was 1 hour of hypothermic cardioplegic arrest followed by controlled reperfusion. Group 4 did not have an ischemic interval. Immediately before reperfusion, a balloon was inserted into the left ventricle in all four groups. The balloon was inflated to $0,10,20$, or $0 \mathrm{~mm} \mathrm{Hg}$, respectively, for groups 1 to 4 . All four groups were reperfused with $38^{\circ} \mathrm{C}$ blood cardioplegic solution. At 30 seconds, 3 minutes, and 6 minutes after reperfusion, microsphere injections 2, 3, and 4 were given. At 7 minutes after the start of reperfusion, the balloon was removed and replaced with a venting catheter. Microsphere injection No. 5 was given after 10 minutes of reperfusion in beating vented hearts. The experiment was terminated at 20 minutes after reperfusion. $C P B$, Cardiopulmonary bypass; $A S$, asystole; $C P$ arrest, cardioplegic arrest; $L V$, left ventricular.

data that reperfusion after hypothermic cardioplegic arrest caused coronary vascular regulation to become abnormal within 3 minutes after the start of postcardioplegia reperfusion.

The present study is intended to confirm and extend the aforementioned study by determining the effect of left ventricular distention on myocardial blood flow during the initial 20 minutes of postcardioplegia reperfusion. The hypothesis is that coronary vascular regulation becomes abnormal within 3 minutes after the start of postcardioplegia reperfusion.

\section{Methods}

Experimental design. Postcardioplegia reperfusion was studied in an intact porcine model during cardiopulmonary bypass as outlined in Fig. 1. All animals in this study received humane care in compliance with the "Principles of Laboratory Animal Care" formulated by the National Society for Medical Research and the "Guide for the Care and Use of Laboratory Animals" prepared by the Institute of Laboratory Animal Resources and published by the National Institutes of Health (NIH Publication No. 93-23, revised 1985).

The methods used in this study are similar to those used in a previous study from this laboratory. ${ }^{15}$ Forty pigs of both sexes were intubated and mechanically ventilated. A median sternotomy was performed and the heart was cannulated for cardiopulmonary bypass. The cardiopulmonary bypass circuit consisted of a bubble oxygenator (Bentley-5 oxygenator, American Bentley Corp., Irvine, Calif.), crystalloid priming solution, and a calibrated roller pump to deliver a systemic flow of 2.0 to $2.2 \mathrm{~L} / \mathrm{min}$ per square meter at $38^{\circ} \mathrm{C}$ and 1.8 to $2.0 \mathrm{~L} / \mathrm{min}$ per square meter at $30^{\circ} \mathrm{C}$. A catheter was placed approximately $2 \mathrm{~cm}$ into the coronary sinus for blood sampling. A purse-string suture was placed into the apex of the left ventricle for venting during ischemia and for placement of a highly compliant latex balloon into the cavity of the left ventricle 
Table I. Composition of blood cardioplegia (BCP) solutions

\begin{tabular}{lcc}
\hline & BCP solution I & BCP solution II \\
\hline $\mathrm{K}^{+}(\mathrm{mmol} / \mathrm{L})$ & $8-10$ & $22-25$ \\
$\mathrm{pH}$ & $7.7-7.8$ & $7.7-7.8$ \\
$\mathrm{Ca}++(\mathrm{mmol} / \mathrm{L})$ & $0.5-0.7$ & $0.5-0.7$ \\
Osm $(\mathrm{mOsm} / \mathrm{kg})$ & $340-360$ & $340-360$ \\
\hline
\end{tabular}

Crystalloid component: $\mathrm{KCl}$ ( $2 \mathrm{mmol} / \mathrm{ml}) 5 \mathrm{ml}$ or $20 \mathrm{ml}$; tromethamine $(0.3$ $\mathrm{mol} / \mathrm{L}$ ) $100 \mathrm{ml}$; citrate-phosphate-dextrose $25 \mathrm{ml} ; 1: 4$ ratio of $5 \%$ dextrose to normal saline solution $(275 \mathrm{ml})$.

during reperfusion. In the aortic root, an infusion cannula with a pressure monitoring port (cannula model 33009, DLP, Inc., Grand Rapids, Mich.) was placed and connected to a calibrated roller pump that was linked to a data acquisition system via an optical tachymeter (model 8200-50, Cole-Parmer, Chicago, Ill.).

The pigs were supported with cardiopulmonary bypass at $38^{\circ} \mathrm{C}$ and the left ventricle was vented. The aorta was clamped and warm $\left(38^{\circ} \mathrm{C}\right)$ blood cardioplegic solution developed by Buckberg ${ }^{16}$ (solution II; Table I) was infused into the aortic root at a mean pressure of $70 \mathrm{~mm} \mathrm{Hg}$. After the heart became asystolic and aortic root flow stabilized, the first microsphere injection $(15 \mu \mathrm{m}$ microspheres) was administered into the clamped aortic root. The aortic clamp was removed 20 seconds after the microsphere injection was completed. The systemic perfusate temperature was then decreased to $30^{\circ} \mathrm{C}$. When the heart regained a normal sinus rhythm, the aorta was again clamped and cold $\left(4^{\circ} \mathrm{C}\right)$ cardioplegic solution II was administered at a mean aortic pressure of $70 \mathrm{~mm} \mathrm{Hg}$ for 3 minutes. Topical saline slush was placed around the heart. Twenty and 40 minutes after the onset of cardioplegic arrest, cold blood cardioplegic solution I (Table I) was given for 1 minute at a mean pressure of $70 \mathrm{~mm} \mathrm{Hg}$. Groups 1, 2, and 3 ( $n=10$ pigs per group) had 60 minutes of hypothermic cardioplegic arrest. Group 4 ( $n=10$ pigs) did not receive cold blood cardioplegic solution. Instead, they had 60 minutes of controlled normothermic perfusion using oxygenator-derived blood without an ischemic interval.

Just before the onset of reperfusion, the vent was removed and a latex balloon that was highly compliant within the volume range required was inserted into the left ventricle. The left ventricular intracavitary pressure was set at $0,10,20$, or $0 \mathrm{~mm} \mathrm{Hg}$ for groups 1,2, 3, and, 4 respectively, by inflating the balloon to the required pressure with air.

All hearts underwent controlled reperfusion with warm $\left(38^{\circ} \mathrm{C}\right)$ blood cardioplegic solution I at a mean pressure of $70 \mathrm{~mm} \mathrm{Hg}$ into the clamped aortic root. This maintained asystole throughout the initial $7 \mathrm{~min}$ utes of reperfusion. The latex balloon was removed after 7 minutes of reperfusion and the venting catheter was replaced to decompress the left ventricle. After the 7-minute controlled infusion of warm blood cardioplegic solution was completed, unmodified oxygenator-derived blood was perfused through the heart at a mean pressure of $70 \mathrm{~mm} \mathrm{Hg}$. Ventricular pacing at a cycle length of $1000 \mathrm{msec}$ was started 30 seconds before the final microsphere injection if the heart remained asystolic at 9 minutes and 30 seconds after the start of reperfusion.

At 30 seconds, 3 minutes, and 6 minutes after reperfusion, microsphere injections 2,3 , and 4 were given to asystolic hearts. Microsphere injection No. 5 was given at 10 minutes after reperfusion in beating vented hearts.

Blood samples from the aortic root and from a catheter in the coronary sinus were collected before cardiopulmonary bypass, during cardiopulmonary bypass, and at specific intervals during the 20 minutes of reperfusion.

Experimental variables. The biochemical variables measured in this study included aortic root and coronary sinus blood gases, oxygen contents, hemoglobin saturations, hemoglobin contents, electrolyte concentrations, and lactate concentrations. Oxygen content was measured with a Lex- $\mathrm{O}_{2}$-Con device (Hospex Fiberoptics, Inc., Chestnut Hill, Mass.). Blood gas determinations were made with a Ciba-Corning model 238 $\mathrm{pH} /$ blood gas analyzer (Ciba-Corning Diagnostics Ltd., Halstead, Essex, United Kingdom), and hemoglobin saturation was measured with an IL model 282 CoOximeter (Instrumentation Laboratories, Inc., Norcross, Ga.). Lactate determinations were made with a COBAS-FARA II analyzer (Roche Diagnostic Systems, Montclair, N.J.).

The hemodynamic variables included systemic arterial and aortic root blood pressures (phasic and mean) and left ventricular intracavitary pressures (mean). Other measured variables included (1) limb lead electrocardiogram, (2) myocardial septal temperature (model NTM-100, Digital Thermometer, Webster Laboratories, Inc., Baldwin Park, Calif.), (3) bypass flow rate (calibrated roller pump), and (4) myocardial tissue weights (obtained post mortem). The electrophysiologic and pressure signals were amplified (amplifier models 20-4615-58 and 13-G4615-64A, Gould Electronics, Cleveland, Ohio) and digitized at a rate of $1.0 \mathrm{kHz}$ per channel. Data were stored on hard disk or optical disk for subsequent analysis (CODAS software; DATAQ, Inc., Akron, Ohio).

Derived variables included myocardial arterial-coronary sinus oxygen content difference, myocardial oxygen consumption, and myocardial lactate gradient.

Regional myocardial blood flow distribution. The regional blood flow determinations were made by cutting the entire heart into 129 sections of myocardium. Sections from the left ventricular apex that were within or immediately adjacent to the apical vent purse-string suture were discarded. The sections from the left ventricular free wall and ventricular septum were divided into subepicardial, midmyocardial, and subendocardial sections of equal thickness. The sections from the right ventricle were divided into subepicardial and subendocardial sections only. The section were weighed and then assayed for gamma emission (model 1282 CompuGamma gamma counter, LKB-Wallac, Turku, Finland). Raw counts were converted to individual isotope counts by the matrix inversion method. Regional blood flows were calculated from the measured aortic root flow, tissue weight, and individual isotope counts.

Statistical analysis. The data were analyzed with SAS-PC software (SAS Iristitute, Inc., Cary, N.C.) and then displayed with Sigma Plot software (Jandel Scientific, 
Table II. Global myocardial blood flow (by calibrated pump)

\begin{tabular}{lccccccc}
\hline & & \multicolumn{5}{c}{ Reperfusion (\% control $\pm S D)$} \\
\cline { 3 - 7 } Group & Before ischemia & $30 \mathrm{sec}$ & $3 \mathrm{~min}$ & $6 \mathrm{~min}$ & $10 \mathrm{~min}$ & $15 \mathrm{~min}$ & $20 \mathrm{~min}$ \\
\hline $1(0 \mathrm{~mm} \mathrm{Hg})$ & $100 \%$ & $159 \pm 26^{*} \dagger$ & $65 \pm 7 \dagger$ & $56 \pm 7 \dagger$ & $51 \pm 6 \dagger$ & $47 \pm 5 \dagger$ & $53 \pm 5 \dagger$ \\
$2(10 \mathrm{~mm} \mathrm{Hg})$ & $100 \%$ & $143 \pm 16 \dagger$ & $96 \pm 26$ & $63 \pm 6 \dagger$ & $51 \pm 4 \dagger$ & $47 \pm 4 \dagger$ & $53 \pm 8 \dagger$ \\
$3(20 \mathrm{~mm} \mathrm{Hg})$ & $100 \%$ & $107 \pm 10$ & $60 \pm 6 \dagger$ & $51 \pm 5 \dagger$ & $48 \pm 5 \dagger$ & $46 \pm 4 \dagger$ & $49 \pm 5 \dagger$ \\
$4(0 \mathrm{~mm} \mathrm{Hg}$, no insert) & $100 \%$ & $92 \pm 11$ & $82 \pm 15$ & $84 \pm 11 \S$ & $82 \pm 10 \dagger$ & $84 \pm 9 \dagger$ & $94 \pm 11 \dagger$ \\
\hline
\end{tabular}

${ }^{*} p<0.05$, group 1 versus groups 3 and 4 .

$\grave{i p}<0.05$ versus control.

$\grave{t} p<0.05$, group 4 versus groups 1,2 , and 3 .

$\$ p<0.05$, group 4 versus groups 1 and 3 .

Table III. Left ventricular free wall endocardial blood flow (measured by microsphere method)

\begin{tabular}{|c|c|c|c|c|c|}
\hline \multirow[b]{2}{*}{ Group } & \multirow[b]{2}{*}{ Before ischemia } & \multicolumn{4}{|c|}{ Reperfusion (\% control $\pm S D$ ) } \\
\hline & & $30 \mathrm{sec}$ & $3 \min$ & $6 \mathrm{~min}$ & $10 \mathrm{~min}$ \\
\hline $1(0 \mathrm{~mm} \mathrm{Hg})$ & $100 \%$ & $157 \pm 15^{*}$ & $63 \pm 6^{*}$ & $62 \pm 7^{*}$ & $47 \pm 6^{*}$ \\
\hline $2(10 \mathrm{~mm} \mathrm{Hg})$ & $100 \%$ & $125 \pm 13$ & $88 \pm 25$ & $60 \pm 5^{*}$ & $36 \pm 3^{*}$ \\
\hline $3(20 \mathrm{~mm} \mathrm{Hg})$ & $100 \%$ & $92 \pm 14+$ & $47 \pm 5^{*}$ & $39 \pm 5^{*}$ & $38 \pm 4^{*}$ \\
\hline 4 (0 mm Hg, no ischemia) & $100 \%$ & $81 \pm 18 \div$ & $80 \pm 22$ & $98 \pm 22 \uparrow$ & $71 \pm 12 * \dagger$ \\
\hline
\end{tabular}

$* p<0.05$ versus control.

$\dagger p<0.05$, group 4 versus groups 1,2 , and 3 .

ip $<0.05$ versus group 1.

Table IV. Left ventricular free wall epicardial blood flow (measured by microsphere method)

\begin{tabular}{|c|c|c|c|c|c|}
\hline \multirow[b]{2}{*}{ Group } & \multirow[b]{2}{*}{ Before ischemia } & \multicolumn{4}{|c|}{ Reperfusion (\% control $\pm S D)$} \\
\hline & & $30 \mathrm{sec}$ & $3 \min$ & $6 \min$ & $10 \mathrm{~min}$ \\
\hline $1(0 \mathrm{~mm} \mathrm{Hg})$ & $100 \%$ & $145 \pm 21$ & $70 \pm 6^{*}$ & $56 \pm 6^{*}$ & $59 \pm 4^{*}$ \\
\hline $2(10 \mathrm{~mm} \mathrm{Hg})$ & $100 \%$ & $121 \pm 13$ & $94 \pm 20$ & $62 \pm 5^{*}$ & $58 \pm 4^{*}$ \\
\hline $3(20 \mathrm{~mm} \mathrm{Hg})$ & $100 \%$ & $101 \pm 8$ & $65 \pm 5^{*}$ & $54 \pm 5^{*}$ & $56 \pm 6^{*}$ \\
\hline $4(0 \mathrm{~mm} \mathrm{Hg}$, no ischemia) & $100 \%$ & $96 \pm 15 \ddagger$ & $86 \pm 18$ & $73 \pm 12$ & $86 \pm 13 \dagger$ \\
\hline
\end{tabular}

${ }^{*} p<0.05$ versus control.

tp<0.05, group 4 versus groups 1,2 , and 3 .

$\ddagger p<0.05$ versus group 1 .

Table V. Endocardial/epicardial blood flow ratios (measured by microsphere method)

\begin{tabular}{lccccc}
\hline & & \multicolumn{4}{c}{ Reperfusion (\% control $\pm S D)$} \\
\cline { 3 - 6 } Group & Before ischemia & $30 \mathrm{sec}$ & $3 \min$ & $6 \mathrm{~min}$ & $10 \mathrm{~min}$ \\
\hline $1(0 \mathrm{~mm} \mathrm{Hg})$ & $100 \%$ & $115 \pm 8$ & $94 \pm 9$ & $114 \pm 11$ & $79 \pm 7^{*}$ \\
$2(10 \mathrm{~mm} \mathrm{Hg})$ & $100 \%$ & $106 \pm 7$ & $89 \pm 4^{*}$ & $97 \pm 5$ & $62 \pm 3^{*}$ \\
$3(20 \mathrm{~mm} \mathrm{Hg})$ & $100 \%$ & $90 \pm 8$ & $72 \pm 5^{*}$ & $73 \pm 6^{*} \dagger$ & $70 \pm 5^{*}$ \\
$4(0 \mathrm{~mm} \mathrm{Hg}$, no ischemia) & $100 \%$ & $82 \pm 12 \uparrow$ & $88 \pm 12$ & $132 \pm 17$ & $86 \pm 9$ \\
\hline
\end{tabular}

${ }^{*} p<0.05$ versus control.

$\dagger p<0.05$ versus group 1 .

Corte Madera, Calif.). Statistical comparisons were made with analysis designs contained in the Means and the General Linear Models procedures of SAS-PC. Duncan's multiple range test was used to scan the variables for significant differences between groups at any given sample time. A least-squares means test was used to cvaluate specific preplanned comparisons between groups. Withingroup comparisons to control values were performed with a paired Student's $t$ test. The level of significance chosen for this study was a $p$ value of less than 0.05 . 


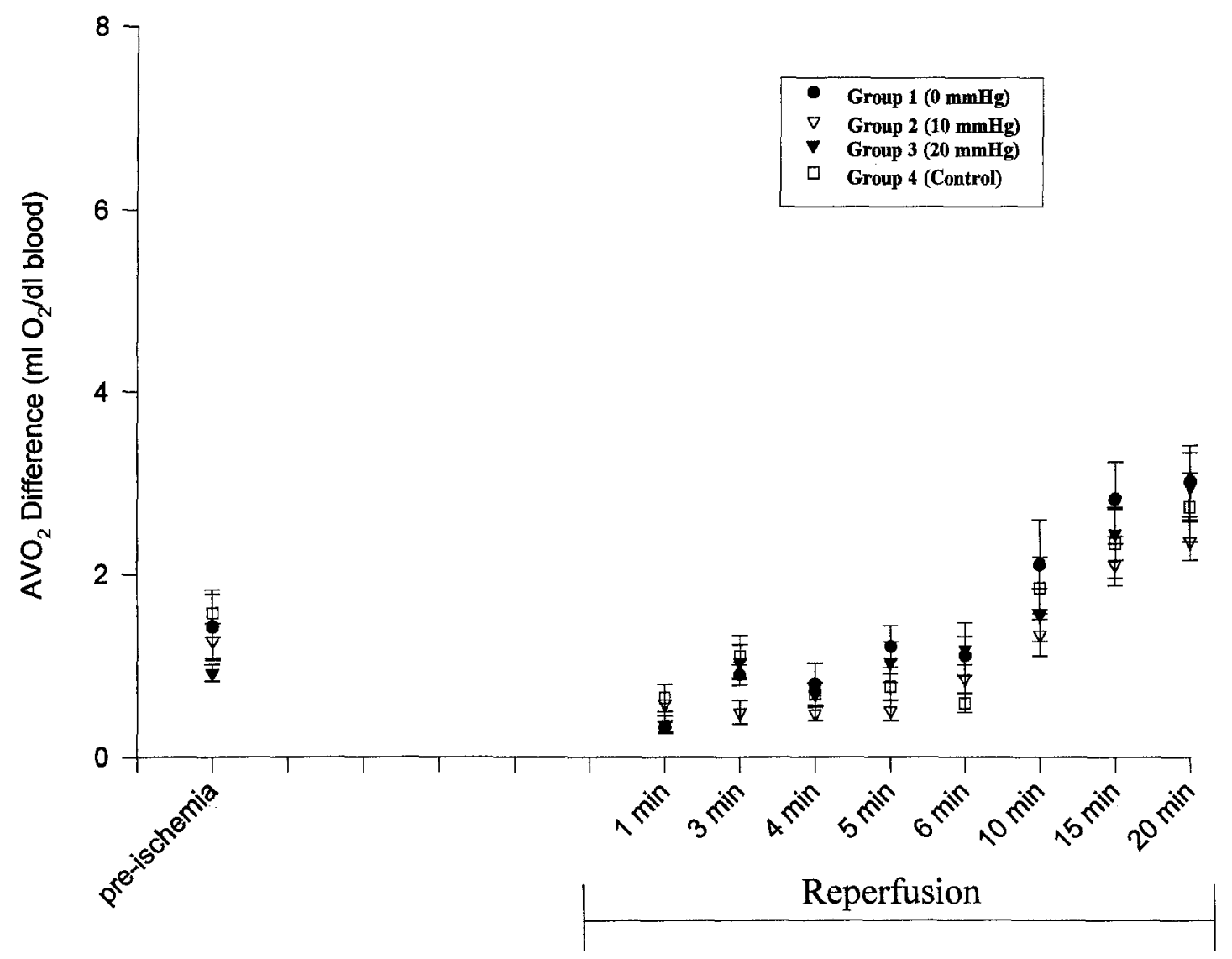

Fig. 2. Myocardial arteriovenous oxygen content difference $\left(\mathrm{AVO}_{2}\right)$ for groups 1 to 4 calculated before cardioplegic arrest and during reperfusion.

\section{Results}

\section{Myocardial blood flow distribution}

Within-group comparisons. In group 1 , global myocardial blood flow at 30 seconds after reperfusion was significantly greater than the preischemic global blood flow. The increased flow at 30 seconds after reperfusion was followed by a decrease in flow during the remaining 20 minutes of reperfusion (Table II). In groups 1 and 3, global myocardial blood flow beginning 3 minutes after reperfusion was significantly lower than control values obtained before ischemia. Global myocardial blood flow in group 2 fell significantly below the control value at 6 minutes after reperfusion. Global myocardial blood flow in group 4 (no ischemic interval or distention) during reperfusion was slightly reduced from the preischemic flow; however, this decrease did not attain statistical significance (Table II).

Between group comparisons of global myocardial blood flow. Global myocardial blood flow at 30 seconds after reperfusion was significantly greater in group $1(0 \mathrm{~mm} \mathrm{Hg}$ left ventricular intracavitary pressure) than in group $3(20 \mathrm{~mm} \mathrm{Hg}$ left ventricular intracavitary pressure) or in group 4 (no ischemic interval and no distention). Intergroup comparisons failed to demonstrate any significant differences in global myocardial blood flow among groups 1,2 , and 3 beginning 3 minutes after the onset of reperfusion. However, the global myocardial blood flow for groups 1,2, and 3 was significantly less than for group 4 at 10,15, and 20 minutes after the onset of reperfusion (Table II).

Within-group and between-group analysis of regional blood flow data. The pattern of decreasing myocardial blood flow during reperfusion noted by the analysis of global myocardial blood flow was also seen in the analysis of regional blood flow data (i.e., endocardial and epicardial flows for the left ventricular free wall) (Tables III and IV).

An effect of left ventricular distention on regional blood flow distribution was found. Between-group comparisons showed that endocardial blood flow was 


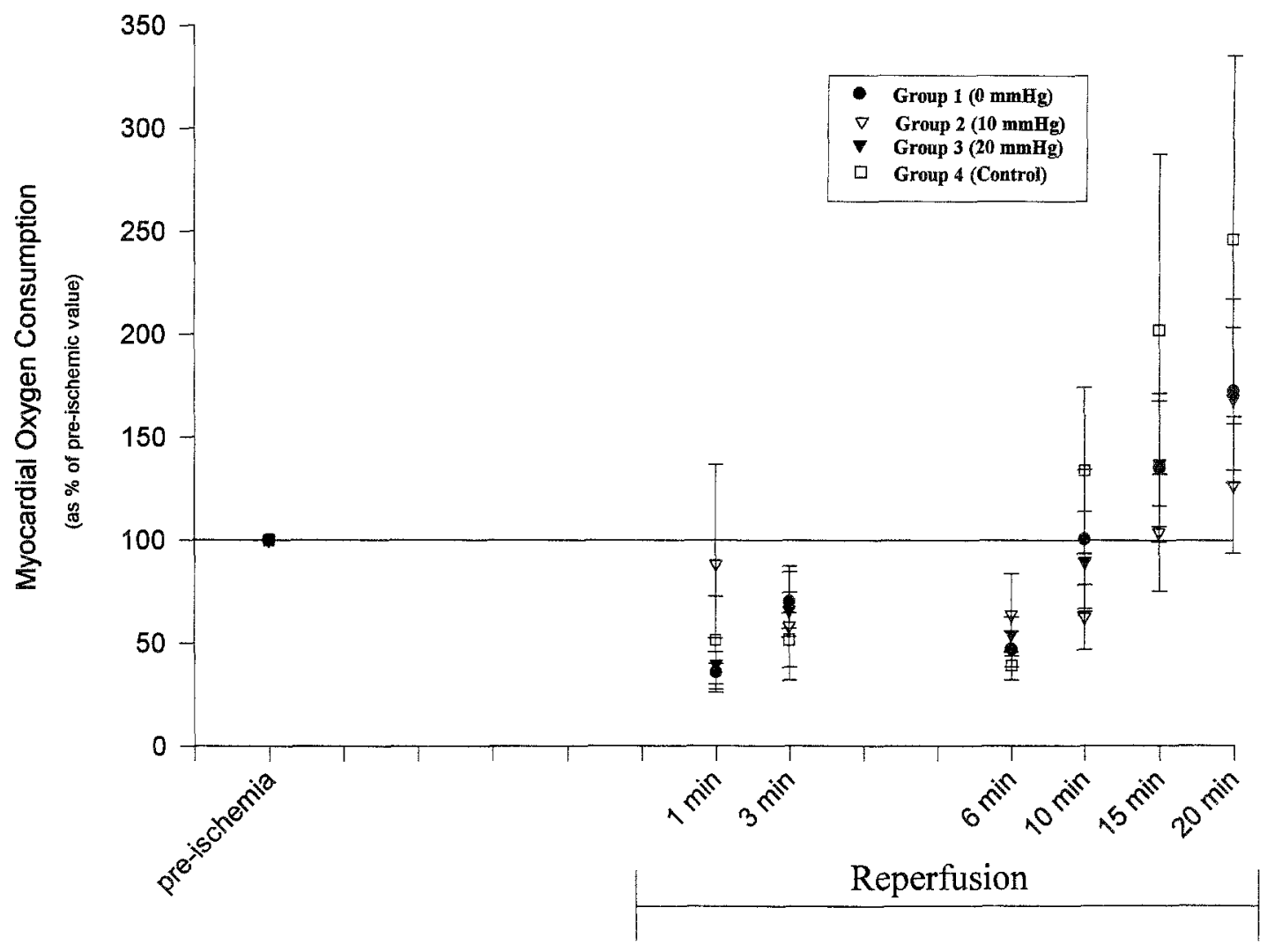

Fig. 3. Myocardial oxygen consumption during postcardioplegia reperfusion was measured and then expressed as a percentage of the preischemic control value.

significantly lower in groups 3 and 4 at 30 seconds after reperfusion than in group 1 (Table III). Furthermore, the endocardial/epicardial flow ratio was significantly lower in group 3 than in group 1 at 6 minutes after reperfusion (Table IV). Comparison of the endocardial/epicardial flow ratios for groups 1 and 3 at 30 seconds and 3 minutes after reperfusion showed lower ratios in group 3 . However, these statistical comparisons did not attain significance $(p=0.057$ and $p=$ 0.052 for each comparison).

Within-group comparisons of left ventricular free wall endocardial and epicardial blood flow showed that by 6 minutes after reperfusion, regional myocardial blood flows for groups 1, 2, and 3 were significantly less than the control values obtained before cardioplegic arrest.

Oxygen consumption. Arterial-coronary sinus oxygen content differences were similar in groups 1 to 4 throughout reperfusion (Fig. 2). Myocardial oxygen consumption was less than preischemic oxygen consumption during the initial 5 minutes of reperfusion. This difference, however, did not attain statistical significance. Myocardial oxygen consump- tion gradually increased during the remainder of reperfusion (Fig. 3). An analysis of the myocardial oxygen consumption data during the 20 minutes of reperfusion did not show any significant betweengroup differences.

Lactate gradient. An analysis of the transmyocardial lactate flux did not show any significant differences among groups 1 to 3 during the study (Fig. 4). The transmyocardial lactate gradient in group 4 was relatively constant throughout the study. Lactate washout was complete within 3 minutes after the start of reperfusion.

Electrolyte data (sodium, potassium, and calcium). Sodium and calcium concentrations in the aortic root during the initial 6 minutes of reperfusion were significantly lower in all groups than the prebypass control values. Ten minutes after the onset of reperfusion, aortic root sodium and calcium concentrations were similar to prebypass values.

Potassium concentrations in the aortic root were significantly higher than prebypass control values during the initial 6 minutes of postcardioplegia reperfusion (Fig. 5). Potassium concentrations in 


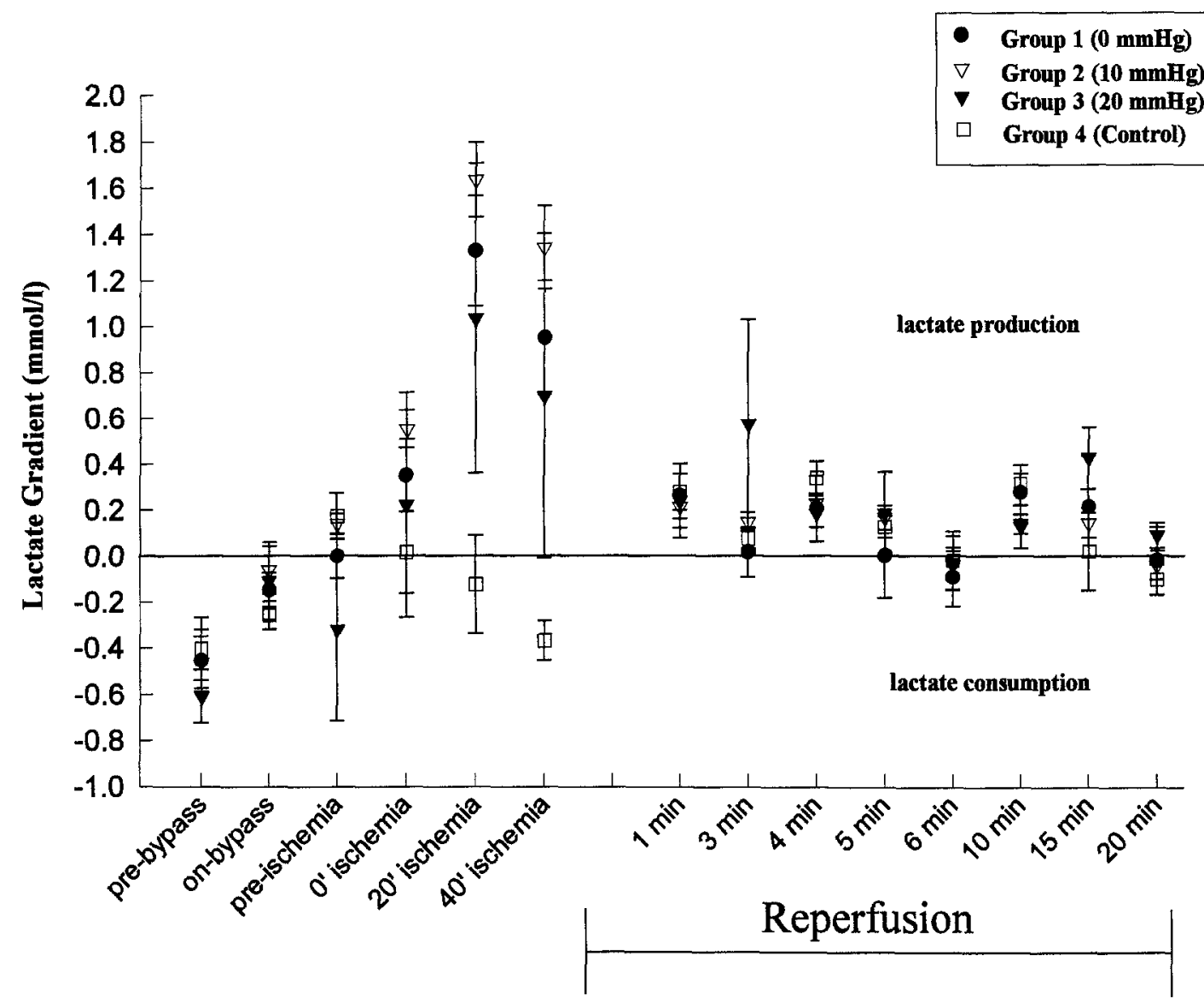

Fig. 4. Measurement of transmyocardial lactate gradient (aortic lactate - coronary sinus lactate concentrations) confirmed myocardial lactate production during hypothermic cardioplegic arrest. There were no significant differences among the three experimental groups during postcardioplegia reperfusion.

the aortic root were at the prebypass control level by 10 minutes after reperfusion.

\section{Discussion}

The hypothesis of the present study is that coronary vascular regulation becomes abnormal within 3 minutes after the start of postcardioplegia reperfusion. The hypothesis was tested by examining the response of the coronary circulation to 7 minutes of left ventricular distention during the initial $20 \mathrm{~min}$ utes of reperfusion after hypothermic blood cardioplegic arrest. Findings include the following: (1) Left ventricular distention attenuated hyperemia after hypothermic cardioplegic arrest; (2) left ventricular distention during asystolic reperfusion caused a significant decrease in the endocardial/ epicardial blood flow ratio at 6 minutes after reperfusion; (3) global myocardial blood flow progressively decreased during the initial 20 minutes of postcardioplegia reperfusion in distended and in nondistended hearts; and (4) after 3 minutes of reperfusion, global myocardial blood flow was significantly less than preischemic blood flow despite the return of electromechanical activity during reperfusion.

Increasing myocardial vascular resistance during the initial minutes of postcardioplegia reperfusion has now been observed in two animal studies from this laboratory. These two laboratory studies corroborate postcardioplegia global myocardial blood flow data obtained by Digerness and associates ${ }^{17}$ in human beings during coronary bypass grafting operations.

In the present study the onset of electromechanical activity did not elicit a blood flow response in experimental groups 1 through 3 , suggesting that metabolic flow recruitment is abnormal after hypothermic blood cardioplegic arrest. This inference 


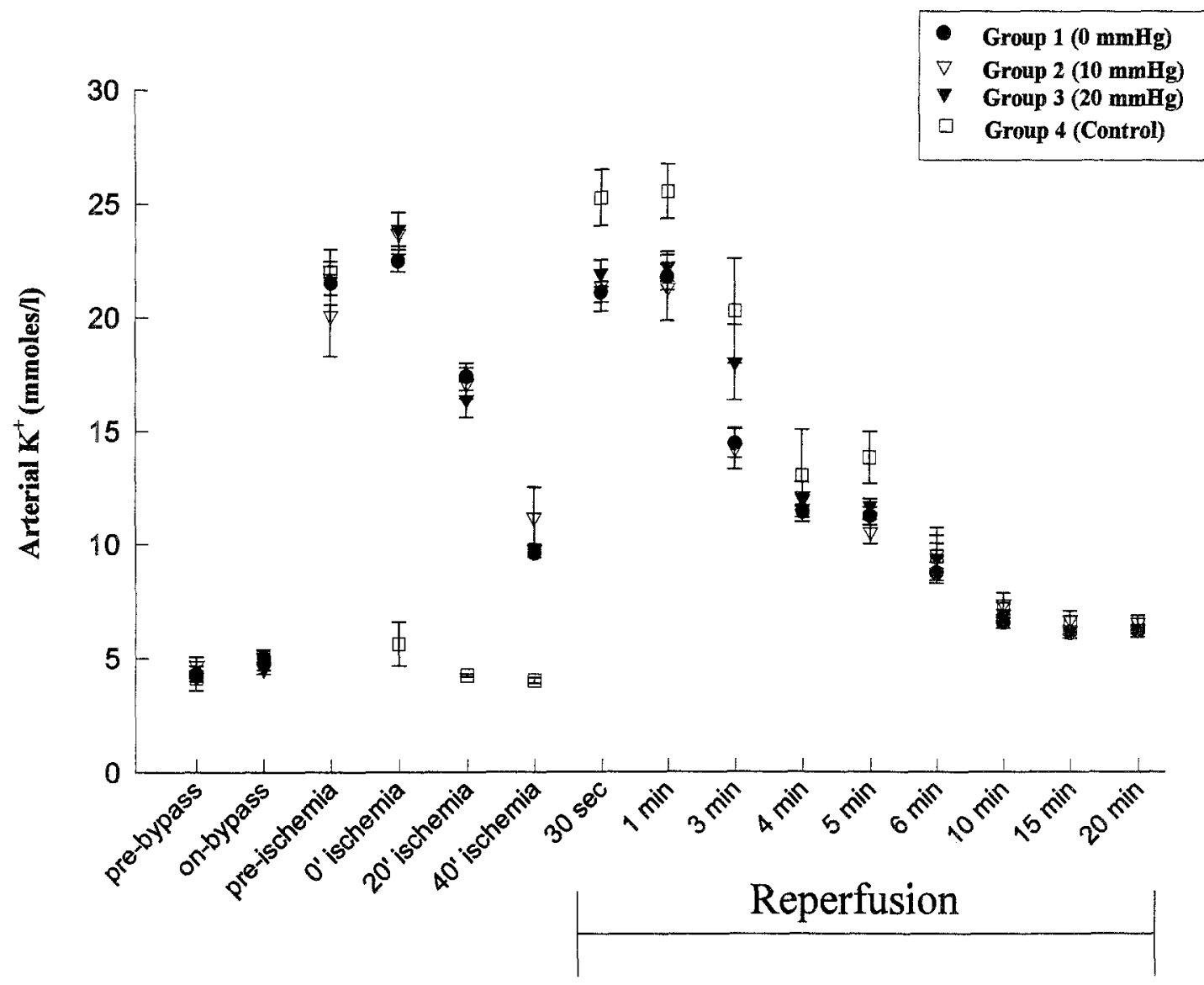

Fig. 5. The arterial (i.e. aortic root) potassium during the experiment did not vary significantly among experimental groups 1 to 3 before ischemia and during reperfusion. Washout was complete within 10 minutes after initiating reperfusion.

regarding metabolic flow recruitment is supported by the finding that ventricular distention decreases the endocardial/epicardial blood flow ratio. Prior work by Domenech showed that diastolic ventricular hypertension (i.e., a ventricular intracavitary pressure from 35 to $45 \mathrm{~mm} \mathrm{Hg}$ ) produces a transmurally homogeneous increase in left ventricular blood flow when coronary autoregulation is intact. However, diastolic ventricular hypertension results in a decrease of subendocardial blood flow relative to subepicardial blood flow after coronary autoregulation is abolished. ${ }^{18}$

An increase in myocardial vascular resistance and the inability of the heart to modulate blood flow according to metabolic demand during the initial 10 to 20 minutes of postcardioplegia reperfusion may be important factors in postcardioplegia reperfusion injury. However, the questions of whether metabolic flow recruitment is abnormal during postcardioplegia reperfusion and how long it remains abnormal during postcardioplegia reperfusion remain open. Other investigators have shown that metabolic flow recruitment is intact 45 minutes after reperfusion in asanguineously perfused, isolated rabbit hearts. ${ }^{19,20}$ Additional experiments are required to clarify these issues.

The mechanisms for the observed increase in coronary vascular resistance and insensitivity to myocardial metabolic demand during postcardioplegia reperfusion have yet to be elucidated. Myocardial edema may play a role in increasing coronary vascular resistance by direct compression of small coronary vessels. The changes in resistance occur so rapidly during reperfusion, however, that this mechanism seems unlikely, and the presence of edema alone should not affect the 
response of the coronary vasculature to changes in metabolic demand. Moreover, other investigators have not found myocardial edema to be responsible for increased vascular resistance in the setting of ischemia-reperfusion injury. ${ }^{19,20}$

An alternative explanation for these findings is endothelial injury that occurs after cardioplegic arrest and reperfusion. Attention has recently been focused on the role of endothelial cells in modulating vascular smooth muscle activity and myocardial vascular resistance. Ischemia-reperfusion injury ${ }^{19-22}$ and cardioplegic arrest with reperfusion ${ }^{11,12}$ have been shown to impair endothelium-dependent vasodilation. It is possible that the adverse effects of ventricular distention during reperfusion are mediated by endothelial dysfunction in myocardial resistance vessels.

Current work that links myocardial ischemia and reperfusion to the generation of free radicals is particularly intriguing as an explanation for postcardioplegia endothelial injury. Over the past several years, a strong association has been developed between ischemic myocardial injury and an excess production of reactive oxygen species (e.g., superoxide, hydrogen peroxide, and hydroxyl radical). More recently, it has been observed that superoxide reacts rapidly with nitric oxide, an endotheliumderived relaxation factor whose production is increased during myocardial ischemia. ${ }^{23}$ This reaction not only impairs coronary autoregulation by eliminating the vasorelaxant action of nitric oxide but also yields the potent secondary oxidant peroxynitrite. $^{24,25}$

Further investigation of this putative mechanism for the genesis of ischemia-reperfusion-induced endothelial injury and loss of autoregulation is worthwhile, because it may be possible to diminish the generation of oxyradicals, including peroxynitrite, during reperfusion. ${ }^{26}$ Decreasing the generation of oxyradicals, and thus decreasing the loss of the native vasodilator nitric oxide, may preserve more normal microvascular function and ameliorate postcardioplegia reperfusion injury.

As the next step in evaluating this postulated mechanism for postcardioplegia reperfusion injury, we are evaluating the effects of ischemia duration on global myocardial blood flow during postcardioplegia reperfusion. Measurements of the extents of superoxide production, loss of nitric oxide-dependent vasorelaxation, and peroxynitrite tissue injury in a porcine model of cardioplegic arrest and reperfusion are underway.
We thank David C. Naftel, PhD, for his help in the statistical analysis of these data, and Bruce A. Freeman, $\mathrm{PhD}$, for his assistance with the interpretation of the experimental results.

\section{REFERENCES}

1. Spaan JAE. Basic coronary physiology. In: Coronary blood flow: mechanisms, distribution, and control. Boston: Kluwer Academic, 1991:24-5.

2. Reuben CF, Singh HM, Tector AJ, Kampine JP, Flemma RJ, Lepley D Jr. The dynamics of subendocardial flow during cardiopulmonary bypass. J Thorac Cardiovasc Surg 1975;70: 989-94.

3. Buckberg GD, Brazier JR, Nelson RL, Goldstein SM, McConnell DH, Cooper N. Studies of the effects of hypothermia on regional myocardial blood fow and metabolism during cardiopulmonary bypass. J Thorac Cardiovasc Surg 1977;73:87-94.

4. Hottenrott C, Maloney JV Jr, Buckberg G. Studies of the effects of ventricular fibrillation on the adequacy of regional myocardial flow. J Thorac Cardiovase Surg 1974;68:634-45.

5. Brazier JR, Cooper N, McConnell DH, Buckberg GD. Studies of the effects of hypothermia on regional myocardial blood flow and metabolism during cardiopulmonary bypass. $J$ Thorac Cardiovasc Surg 1977;73:102-9.

6. Downey HF, Crystal GJ, Bashour FA. Asynchronous transmural perfusion during coronary reactive hyperaemia. Cardiovasc Res 1983;17:200-6.

7. Kay HR, Levine FH, Fallon JT, Grotte GJ, Newell J, McEnany MT, et al. Correlation of patterns of subendocardial reperfusion and left ventricular performance after ischemia. Ann Thorac Surg 1981;31:233-9.

8. Rabinov M, Newman M, Smolich JJ, Rosenfeldt FL. Adverse effects of low pressure reperfusion after hypothermic cardioplegia in normal and hypertrophic hearts. J Thorac Cardiovasc Surg 1991;102:695-706.

9. Lucas SK, Schaff HV, Flaherty JT, Gott VL, Gardner TJ. The harmful effects of ventricular distension during post-ischemic reperfusion. Ann Thorac Surg 1981;32:486-94.

10. Lucas SK, Gardner TJ, Elver EB, Flaherty JT, Buckley BH, Gott VL. Comparison of the effects of left ventricular distension during cardioplegia induced ischemic arrest and ventricular fibrillation. Circulation 1980;62:142-9.

11. Keller MW, Geddes L, Spotnitz W, Kaul S, Duling BR. Microcirculatory dysfunction following perfusion with hyperkalemic, hypothermic, cardioplegic solutions and blood reperfusion. Circulation 1991;84:2485-94.

12. Nilsson FN, Miller VM, Vanhoutte PM, McGregor CGA. Methods of cardiac preservation alter the function of the endothelium in porcine coronary arteries. J Thorac Cardiovasc Surg 1991;102:923-30.

13. Pearson PJ, Lin PJ, Schaff HV. Global myocardial ischemia and reperfusion impair endothelium-dependent relaxations to aggregating platelets in the canine coronary artery: a possible cause for vasospasm after cardiopulmonary bypass. $\mathrm{J}$ Thorac Cardiovasc Surg 1992;103:1147-54.

14. Evora PR, Pearson PJ, Schaff HV. Impaired endotheliumdependent relaxation after coronary reperfusion injury: evidence for G-protein dysfunction. Ann Thorac Surg 1994;57: 1550-6.

15. Holman WL, Vicente WA, Spruell RD, Digerness SB, Pacifico AD. Effect of postcardioplegia reperfusion 
rhythm on myocardial blood flow. Ann. Thorac Surg 1994; 58:351-8.

16. Lazar HL, Buckberg GD, Manganaro AM, Becker H. Myocardial energy replenishment and reversal of ischemic damage by substrate enhancement of secondary blood cardioplegia with amino acids during reperfusion. J Thorac Cardiovasc Surg 1980;80:350-9.

17. Digerness SB, Kirklin JW, Naftel DC, Blackstone EH, Kirklin JK, Samuelson PN. Coronary and systemic vascular resistance during reperfusion after global myocardial ischemia. Ann Thorac Surg 1988;46:447-54.

18. Domenech RJ. Regional diastolic coronary blood flow during diastolic ventricular hypertension. Cardiovasc Res 1978;12: 639-45.

19. Seccombe JF, Schaff HV. Coronary artery endothelial function after myocardial ischemia and reperfusion. Ann Thorac Surg 1995;60:778-88.

20. Hashimoto K, Pearson PJ, Schaff HV, Cartier R. Endothelial cell dysfunction after ischemic arrest and reperfusion: a possible mechanism of myocardial injury during reflow. $J$ Thorac Cardiovasc Surg 1991;102:688-94.

21. VanBenthuysen KM, McMurtry IF, Horwitz LD. Reper- fusion after acute coronary occlusion in dogs impairs endothelium-dependent relaxation to acetylcholine and augments contractile reactivity in vitro. $J$ Clin Invest 1987;79:265-74.

22. Ku DD. Coronary vascular reactivity after acute myocardial ischemia. Science 1982;218:576-8.

23. Zweier JL, Wang P, Kuppusamy P. Direct measurement of nitric oxide generation in the ischemic heart using electron paramagnetic resonance spectroscopy. J Biol Chem 1995;270: 304-7.

24. Radi R, Beckman JS, Bush KM, Freeman BA. Peroxynitrite oxidation of sulfhydryls: the cytotoxic potential of superoxide and nitric oxide. J Biol Chem 1991;266:4244-50.

25. Ischiropoulos H, Zhu L, Chen J, Tsai M, Martin JC, Smith $C$, et al. Peroxnitrite-mediated tyrosine nitration catalyzed by superoxide dismutase. Arch Biomech Biophys 1992;298: $431-7$.

26. Rubbo H, Radi R, Trujilo M, Talleri R, Kalyanaraman B, Barnes $S$, et al. Nitric oxide regulation of superoxide and peroxynitrite-dependent lipid peroxidation: formation of novel nitrogen-containing oxidized lipid derivatives. J Biol Chem 1994;269:26066-75. 